\title{
Comparison of EQ-5D-3L and 5L versions following operative fixation of closed ankle fractures
}

\author{
Andrew Garratt ${ }^{1}$ (D) $\cdot$ Knut Stavem ${ }^{2,3,4}$ iD \\ Accepted: 5 February 2022 / Published online: 19 February 2022 \\ (c) The Author(s) 2022
}

\begin{abstract}
Purpose To undertake the first testing and comparison of measurement properties for the EuroQol EQ-5D-3L and 5L in patients with ankle problems.

Methods The cross-sectional postal survey of 959 patients aged $\geq 18$ years, who underwent surgical treatment (ORIF) for unstable and closed ankle fractures in Eastern Norway. Both the EQ-5D-3L and 5L were included in a postal questionnaire in 2015, 3-6 years post surgery. Missing data, floor and ceiling effects, and response consistency were assessed. Tests of validity included comparisons with scores for the SF-36 and widely used ankle-specific instruments. The 5L version was assessed for test-retest reliability.

Results There were 567 (59\%) respondents; 501 completed both versions and 182 (61\%) the 5L retest questionnaire. The $5 \mathrm{~L}$ outperformed the $3 \mathrm{~L}$ in tests of data quality and classification efficiency. Correlations with scores for other instruments largely met expectations, those for the $5 \mathrm{~L}$ being slightly higher. All $5 \mathrm{~L}$ scores had acceptable levels of reliability. For the $5 \mathrm{~L}$ index, the smallest detectable differences for group and individual comparisons were 0.02 and 0.20 , respectively.

Conclusion The $5 \mathrm{~L}$ outperformed the $3 \mathrm{~L}$ in terms of data quality, number of health states assessed and tests of validity. The $5 \mathrm{~L}$ is recommended in research and other applications following surgery for ankle fracture but further testing including responsiveness to change is recommended at clinically relevant follow-up periods.
\end{abstract}

Keywords EQ-5D-3L $\cdot$ EQ-5D-5L $\cdot$ Ankle surgery $\cdot$ Patient-reported outcome measures $\cdot$ PROMs

$\begin{array}{ll}\text { Abbreviations } \\ \text { BMI } & \text { Body Mass Index } \\ \text { ICC } & \text { Intraclass correlation coefficient } \\ \text { LEFS } & \text { Lower extremity function scale } \\ \text { OMAS } & \text { Olerud molander ankle score } \\ \text { ORIF } & \text { Open reduction internal fixation } \\ \text { PROMs } & \text { Patient-reported outcome measures } \\ \text { SDC } & \text { Smallest detectable change }\end{array}$

Andrew Garratt

andrew.garratt@fhi.no

Knut Stavem

knut.stavem@medisin.uio.no

1 Division for Health Services, Norwegian Institute of Public Health, Oslo, Norway

2 Institute of Clinical Medicine, University of Oslo, Oslo, Norway

3 Department of Pulmonary Medicine, Medical Division, Akershus University Hospital, Lørenskog, Norway

4 Health Services Research Unit, Akershus University Hospital, Lørenskog, Norway
SEFAS Self-reported foot and ankle score

SEM Standard error of measurement

EQ-5D EuroQol EQ-5D

\section{Introduction}

The EQ-5D is the most widely used short-form generic patient-reported outcome measure (PROM) suitable for economic evaluation. National scoring algorithms exist for over 20 countries, and it is available in over 170 languages $[1,2]$. The EQ-5D has been widely applied in clinical and health services research, and cost per quality-adjusted life years (QALY) comparisons. National applications include the National Health Service's Patient-Reported Outcome Measures (PROMs) programme for England [3] and Scandinavian medical registers [4-6].

Comprising just six questions or dimensions, the brevity of the EQ-5D has contributed to its application alongside ankle-specific instruments [7], which it complements through its broader focus on general aspects of health and 
suitability for economic evaluation. Furthermore, the availability of EQ-5D population norms, usually from a representative sample of the general population, enables greater understanding of the impact of a health problem or disease on health more generally [2]. Systematic literature searches of PubMed show that the EQ-5D has been used in 28 studies of ankle fractures and/or ankle surgery including 8 randomized controlled trials and 5 economic evaluations. For PROMs to be considered appropriate for such applications it is important that they meet widely recognized measurement criteria including reliability and validity. The scores for ankle-specific PROMs have been compared with those for the EQ-5D in testing the validity of the former $[8,9]$, however, there is no published evaluation of the EQ-5D measurement properties in patients with ankle fractures or ankle problems more generally.

The original version of the instrument with three levels, EQ-5D-3L or 3L, includes five important dimensions of health: mobility, self-care, usual activities, pain/discomfort and anxiety/depression. Each has three levels or response categories: no problem, some problems, severe problems. The five-level version, EQ-5D-5L or 5L, was developed by the EuroQol Group to improve the precision and responsiveness to change $[3,10]$. The $5 \mathrm{~L}$ has been widely adopted across health problems [10], including patients undergoing ankle surgery $[7,11,12]$.

There is increasing evidence for the improved measurement properties of the $5 \mathrm{~L}$ relative to the $3 \mathrm{~L}$, but testing in patient populations, prior to application or concurrently, is necessary [13]. Based on the findings for general and diverse patient populations, one systematic review that included 24 reports of concurrent comparisons, concluded that the $5 \mathrm{~L}$ showed similar or better measurement properties than the $3 \mathrm{~L}$ [10]. More recently, seven further concurrent evaluations of the two versions support these findings, in comparisons of data quality, validity and responsiveness to change [14-20]. Given its widespread application [7-9], it is important that the $5 \mathrm{~L}$ be evaluated for measurement properties in patients with ankle fractures including concurrent evaluation alongside the $3 \mathrm{~L}$, to inform which version is most appropriate in these patients.

The current study is the first to report the concurrent measurement properties of the two versions of the EQ-5D administered to ankle patients as part of a retrospective cohort study 3-6 years post-surgery [7]. The study assesses measurement criteria that have been recommended and widely applied in comparisons of the two versions and follows international standards for reporting on PROMs in such a context $[10,21]$.

\section{Methods}

\section{Data collection}

This cross-sectional postal survey included 959 patients $\geq 18$ years of age, who underwent surgical treatment (ORIF, open reduction internal fixation) for unstable and closed ankle fractures at two hospitals in Eastern Norway 2009-2011 [7, 22]. In January 2015, they received a postal questionnaire that included both versions of the EQ-5D and the EQ VAS with other generic and ankle-specific PROMs [7]. The accompanying letter explained the purpose of the study and that by responding to the questionnaire they gave their informed consent. The ordering of the two versions of the EQ-5D was randomized. Non-respondents received a reminder at 4.5 weeks, and at the same time a test-retest questionnaire was mailed to the first 299 respondents. The latter only included the $5 \mathrm{~L}$ version.

The study was approved by the Norwegian Social Science Data Services (approval no. 28813/5) and the Regional Committee for Medical and Health Research Ethics, Health Region South East (approval no. 2012/384) and was conducted in accordance with the Helsinki Declaration.

\section{Patient-reported outcome measures}

The EQ-5D instrument has a 3L or 5L descriptive system described above, as well as a visual analogue scale, the EQ VAS [3, 10], which is scored separately. Scores for both versions can be aggregated to a single score, the EQ-5D index, estimated using a scoring algorithm from a value set derived from valuation tasks undertaken with general population samples. An algorithm is not yet available for Norway and hence, current recommendations were followed for using algorithms from the UK for both versions and mapping for the $5 \mathrm{~L}$ [23-25]. Scores for the $3 \mathrm{~L}$ and $5 \mathrm{~L}$ range from -0.59 to $1 ; 1$ is the best possible health state. Negative values represent health states perceived as worse than dead. The EQ VAS assesses self-rated health on a vertical VAS, with endpoints labeled "Best imaginable health state" (100) and "Worst imaginable health state" (0) [3].

The SF-36 version 1 is a generic PROM that includes eight health domains of physical functioning, role limitations due to physical problems, bodily pain, general health, vitality, social functioning, role limitations due to emotional problems and mental health [26]. Each domain comprises two to ten items, with two- to six-point descriptive scales, that contribute to eight scores from 0 to 100 scale where 100 is the best possible health. [26, 27].

The Lower Extremity Function Scale (LEFS) has 20 items relating to physical function and daily activities with 
a five-point scale from 'extreme difficulty or unable to perform' to 'no difficulty' [28]. Item scores sum to a 0 to 80 score where 80 is the best possible score. The Olerud Molander Ankle Score (OMAS) has nine items relating to symptoms, physical function and daily activities [29]. Item response scales vary from two to five points, and clinical scoring reflects the level of disability. Items sum to a score from 0 to 100 where 100 is best possible. The Self-Reported Foot and Ankle Score (SEFAS) has twelve items relating to pain, limping, swelling, use of orthotics and walking [8]. The Norwegian translation followed the Swedish SEFAS [8], with a forward-backwards translation of the original English version [30] and has acceptable measurement properties [7]. The five-point scales reflect item content and sum to a 12 to 60 score where 12 is normal function. Mean imputation was used for the SF-36 and ankle-specific instruments when half or more items were completed $[7,26]$.

\section{Statistical analysis}

Levels of missing data were assessed for both the $3 \mathrm{~L}$ and 5L. To facilitate further comparisons, only respondents with complete data for the $3 \mathrm{~L}$ and $5 \mathrm{~L}$ were included. Response frequencies including floor (poorest level of health) and ceiling (best level of health) effects were assessed for both versions including the five items, single index, and EQ VAS. Various criteria have been proposed for acceptable levels of floor and ceiling effects including 15\% [31]. More recent guidelines have not included explicit criteria, but such information is important for the interpretation of measurement properties [21, 32]. This survey was a long-term follow-up and a high proportion of respondents scoring at the ceiling was expected. Fewer were expected to score at the floor. If the additional two response categories make an important contribution, then fewer respondents might be expected to use these response categories for the $5 \mathrm{~L}$ compared to the $3 \mathrm{~L}$.

Following published comparisons of the $3 \mathrm{~L}$ and $5 \mathrm{~L}$, classification efficiency was assessed using Shannon's indices of $\mathrm{H}^{\prime}$, which assesses the extent to which information is evenly distributed across response categories, and $\mathrm{J}^{\prime}$, which also takes account of the number of response categories [10].

$$
H^{\prime}=\sum_{i=1}^{R} p_{i} \ln p_{i}
$$

$J^{\prime}=H^{\prime} / H^{\prime} \max$

$\mathrm{H}^{\prime}$ can range from 0 to 1.58 for the $3 \mathrm{~L}$ and from 0 to 2.32 for the $5 \mathrm{~L}$, where higher values indicate greater efficiency. $\mathrm{J}^{\prime}$ can range from 0 to 1 where 1 is greater efficiency with responses evenly distributed across response categories.
Response consistency was assessed in the same manner to existing comparisons of the $3 \mathrm{~L}$ and $5 \mathrm{~L}[10,14$, 15]. There are 15 potential $3 \mathrm{~L}-5 \mathrm{~L}$ response pairs for each dimension. After transforming $3 \mathrm{~L}$ response categories (1, $2,3)$ to those for the $5 \mathrm{~L}(1,3,5)$, differences of more than one category are defined as inconsistencies [10].

Reliability of index scores was assessed with the intraclass correlation coefficient within a two-way mixed effects model with absolute agreement [7, 32]. Following published recommendations [32], kappa with quadratic weighting [33] was used for assessing individual item reliability. The standard error of measurement (SEM) and smallest detectable change (SDC) were calculated. The former is the square root of the total error variance. For individuals the SDC is $1.96 \times \sqrt{ } 2 \times$ SEM and for groups, the SDC for individuals is divided by $\sqrt{ } \mathrm{n}$ [32].

In tests of validity, it was hypothesized that compared to the $3 \mathrm{~L}, 5 \mathrm{~L}$ dimension scores would have higher correlations with those for the EQ VAS. Hypothesis testing was also used to assess the validity of the two sets of EQ-5D scores through comparisons with those for the SF-36 and ankle-specific instruments based on criteria for a systematic review of generic PROMs [34]:

(1) Correlations $\geq 0.60$ were expected for scores assessing the same construct: EQ-5D (mobility, usual activities) and SF-36 physical functioning; EQ-5D usual activities and SF-36 role-physical; EQ-5D pain and SF-36 bodily pain; EQ-5D anxiety/depression and SF-36 mental health. This level of correlation was also expected for the EQ-5D (index, mobility, usual activities, pain/discomfort), EQ VAS and ankle-specific instrument scores. The index and EQ VAS scores were also expected to have correlations $\geq 0.60$ with those for SF-36 general health and domains contributing most to physical health; physical function, role-physical, bodily pain.

(2) Correlations $<0.60$ and $\geq 0.30$ were expected for instrument scores assessing related but dissimilar constructs: EQ-5D (self-care, pain/discomfort) and SF-36 physical function; EQ-5D (mobility, self-care, pain discomfort) and SF-36 role-physical; EQ-5D (mobility, usual activities) and SF-36 bodily pain; all five EQ-5D dimensions and SF-36 general health; EQ-5D (mobility, usual activities) and SF-36 social function; EQ-5D anxiety/ depression and SF-36 role-emotional. The index and EQ VAS scores were also expected to have correlations $<0.60$ and $\geq 0.30$ with those for the SF-36 contributing most to mental aspects of health: vitality, role-emotional and mental health.

(3) Correlations $<0.50$ and $\geq 0.20$ for scores assessing moderately related but dissimilar constructs: remaining correlations with SF-36 and ankle-specific instruments.

Stata version 15.0 (StataCorp LLC, College Station, TX) was used for statistical analyses. 


\section{Results}

\section{Study population}

There were 567 (59.1\%) respondents to the questionnaire. Table 1 shows the characteristics of the 501 respondents completing both versions of the EQ-5D. There were 182 (60.9\%) respondents to the test-retest questionnaire, at a median (25th-75th percentile) of 41 (39-44) days after the first response.

\section{Data quality}

EQ-5D dimension level missing data was similar for both versions with $527(92.9 \%)$ and $522(92.1 \%)$ respondents completing the five dimensions for the $3 \mathrm{~L}$ and $5 \mathrm{~L}$, respectively. The EQ VAS was correctly completed by 382 (67.4\%) respondents.
Table 2 shows that the vast majority of the 501 respondents completing both the $3 \mathrm{~L}$ and $5 \mathrm{~L}$, reported no problems across four of the five $3 \mathrm{~L}$ and $5 \mathrm{~L}$ dimensions, the exception being pain/discomfort. Except for the response category denoting poorest health for the $5 \mathrm{~L}$ self-care dimension, there were responses to all response categories across the two versions. The 501 respondents had 38,69 and 38 states assessed by the $3 \mathrm{~L}, 5 \mathrm{~L}$ and EQ VAS, respectively.

There were very few responses to the response categories denoting the worst possible health. The greatest number of responses at this level were for the pain/discomfort and anxiety/depression dimensions for the $3 \mathrm{~L}$. The differences with the equivalent $5 \mathrm{~L}$ dimensions were statistically significant. The proportion of responses to the response categories denoting the best possible health, ranged from $39-94 \%$ and from $32-93 \%$ for the $3 \mathrm{~L}$ and $5 \mathrm{~L}$, respectively. Compared to the $3 \mathrm{~L}, 5 \mathrm{~L}$ responses at this level were 5-10\% lower and statistically significant for mobility and pain/discomfort. For the index scores, the $5 \mathrm{~L}$ had $7 \%$ fewer respondents scoring
Table 1 Characteristics of respondents completing both versions of the EQ-5D at 3-6 years follow-up $(n=501)$

\begin{tabular}{|c|c|c|}
\hline & $\mathrm{N}$ & $\%$ \\
\hline Age years, mean (range) & $57.2(22.2-91.2)$ & \\
\hline Female & 284 & 56.7 \\
\hline \multicolumn{3}{|l|}{ Marital status } \\
\hline Divorced/separated & 69 & 13.9 \\
\hline Cohabitant/married & 350 & 70.6 \\
\hline Single & 41 & 8.3 \\
\hline Widowed & 36 & 7.3 \\
\hline \multicolumn{3}{|l|}{ Education } \\
\hline Under 10 years & 142 & 28.7 \\
\hline $10-12$ years & 188 & 38.1 \\
\hline University & 164 & 33.2 \\
\hline Body mass index $\left(\mathrm{kg} / \mathrm{m}^{2}\right)$, median (range) & $27.7(14.4-56.7)$ & \\
\hline Current smoker & 123 & 24.6 \\
\hline Diabetes & 28 & 5.6 \\
\hline \multicolumn{3}{|l|}{ Fracture classification, Weber } \\
\hline A & 12 & 2.4 \\
\hline $\mathrm{B}$ & 338 & 67.5 \\
\hline $\mathrm{C}$ & 139 & 27.7 \\
\hline \multicolumn{3}{|l|}{ Fracture, clinical features } \\
\hline Uni-malleolar & 263 & 53.1 \\
\hline Bimalleolar & 110 & 22.2 \\
\hline Trimalleolar & 122 & 24.6 \\
\hline \multicolumn{3}{|l|}{ Physical status (ASA ${ }^{\mathrm{a}}$ classification) } \\
\hline Completely healthy fit & 178 & 35.5 \\
\hline Mild systemic disease & 300 & 59.9 \\
\hline Severe systemic disease, not incapacitating & 23 & 4.6 \\
\hline Postoperative length of stay in days, median (range) & $7(1-23)$ & \\
\hline Surgery duration in minutes, median (range) & $77(7-352)$ & \\
\hline Waiting time for surgery in days, median (range) & $5(0-64)$ & \\
\hline
\end{tabular}

${ }^{a}$ American Society of Anesthesiologists 
Table 2 Frequencies (\%) and descriptive statistics for the EQ-5D-3L, 5L and EQ VAS ( $\mathrm{n}=501)$

\begin{tabular}{|c|c|c|c|c|c|}
\hline & No problems & Slight problems & $\begin{array}{l}\text { Some/ moderate } \\
\text { problems }\end{array}$ & Severe problems & Unable/extreme \\
\hline \multicolumn{6}{|l|}{ EQ-5D-3L } \\
\hline Mobility & $363(72.5)$ & & $137(13.6)$ & & $1(0.2)$ \\
\hline Self-care & $469(93.6)$ & & $31(6.2)$ & & $1(0.2)$ \\
\hline Usual activities & $360(71.9)$ & & $134(26.7)$ & & $7(1.4)$ \\
\hline Pain/discomfort & $240(47.9)$ & & $242(48.3)$ & & $19(3.8)$ \\
\hline Anxiety/depression & $383(76.4)$ & & 103 (20.6) & & $15(3.0)$ \\
\hline \multicolumn{6}{|l|}{ EQ-5D-5L } \\
\hline Mobility & $336(67.1)^{* *}$ & $109(21.8)$ & $44(8.8)$ & $11(2.2)$ & $1(0.2)$ \\
\hline Self-care & $465(92.8)$ & $26(5.2)$ & $6(1.2)$ & $4(0.8)$ & $0(0.0)$ \\
\hline Usual activities & $357(71.3)$ & $95(19.0)$ & $34(6.8)$ & $13(2.6)$ & $2(0.4)$ \\
\hline Pain/discomfort & $185(36.9)^{* *}$ & $230(45.9)$ & $62(12.4)$ & $20(4.0)$ & $4(0.8)^{* *}$ \\
\hline \multirow[t]{2}{*}{ Anxiety/depression } & $373(74.5)$ & $83(16.6)$ & $28(5.6)$ & $15(3.0)$ & $2(0.0)^{* *}$ \\
\hline & Mean (SD) & Best possible & Worst possible & $\begin{array}{l}\text { Number of health } \\
\text { states }^{\text {a }}\end{array}$ & Range \\
\hline EQ-5D-3L indexb & $0.80(0.23)$ & $195(38.9)$ & $0(0.0)$ & 38 & $-0.25-1$ \\
\hline EQ-5D-5L index & $0.81(0.19)^{* *}$ & $161(32.1)^{* *}$ & $0(0.0)$ & 69 & $-0.26-1$ \\
\hline EQ VAS & $80.71(16.5)$ & $38(10.5)$ & $0(0.0)$ & 38 & $20-100$ \\
\hline
\end{tabular}

${ }^{a}$ Number of possible health states: EQ-5D-3L $=3^{5}$ (243); EQ-5D-5L $=5^{5}(3125)$; EQ VAS $=101$

${ }^{b}$ EQ-5D-5L index scores range from -0.57 to 1 where 1 is the best possible health state, EQ VAS scores range from $0-100$ where 100 is the best possible health state

Asterisks denote statistically significant differences between the $3 \mathrm{~L}$ and $5 \mathrm{~L}$ using McNemar's related-samples change test: $* \mathrm{P}<0.05$; $* * \mathrm{P}<0.01$

1, equal to the best possible health, and this was statistically significant.

\section{Classification efficiency}

Shannon's H' ranged from 0.10 (self-care) to 0.36 (pain/ discomfort) and from 0.14 (self-care) to 0.50 (pain/discomfort) for the $3 \mathrm{~L}$ and $5 \mathrm{~L}$ dimensions, respectively. $\mathrm{J}$ ' ranged from 0.04 (self-care) to 0.15 (pain/discomfort) and from 0.05 (self-care) to 0.22 (pain/discomfort) for the $3 \mathrm{~L}$ and $5 \mathrm{~L}$ dimensions, respectively. The 5L dimensions showed mean information gain ranging from 1.23 (anxiety/depression) to 1.49 (mobility) for $\mathrm{H}^{\prime}$ and from 1.24 (anxiety/depression) to 1.51 (mobility) for $\mathrm{J}$ '.

\section{Response consistency}

Table 3 shows response consistency across the two versions. The great majority of respondents reporting no problems for the $3 \mathrm{~L}$ also report no problems for the $5 \mathrm{~L}$ dimensions; $2-30 \%$ respond with slight problems for the $5 \mathrm{~L}$, the largest shift being for pain/discomfort. Overall, self-care and anxiety/depression had the lowest and highest levels of response inconsistency, respectively. Across the five dimensions (7-17\%), most inconsistencies included respondents reporting some problems on the $3 \mathrm{~L}$ and no problems for the 5L. Several of the other inconsistencies related to just one respondent. There were four exceptions: for mobility, $1 \%$ reported no problems for the $3 \mathrm{~L}$ and moderate problems for the $5 \mathrm{~L}$; for pain/discomfort, $26.3 \%$ reported extreme problems for the $3 \mathrm{~L}$ and moderate problems for the $5 \mathrm{~L}$; for anxiety/depression, $1 \%$ reported no problems for the $3 \mathrm{~L}$ and moderate problems for the 5L; for anxiety/depression $27 \%$ reported extreme problems for the $3 \mathrm{~L}$ and moderate problems for the 5L. The distribution of response inconsistencies was not affected by the ordering of the $3 \mathrm{~L}$ and $5 \mathrm{~L}$ within the questionnaire (Kruskal-Wallis test, $\mathrm{p}<0.05$ ).

\section{Reliability and smallest detectable change}

Table 4 shows that weighted kappa for the individual $5 \mathrm{~L}$ dimensions, and intraclass correlation coefficient for the index and EQ VAS scores, indicated good agreement between test and retest. Only the weighted kappa for the self-care dimension fell well below the criterion of 0.7 for reliability [32]. SEMs ranged from 0.19 to 0.37 for self-care and pain/discomfort dimensions, respectively. The SDC for comparisons of individuals ranged from 0.53 to 1.02 , and for groups, from 0.04 to 0.08 for the same dimensions, respectively. The EQ-5D index had an SEM of 0.07, and SDCs of 0.20 and 0.02 for individuals and groups, respectively. The 
Table 3 Response consistency (\%) between the EQ-5D-5L and EQ-5D-3L ( $\mathrm{n}=501)$

\begin{tabular}{|c|c|c|c|c|c|}
\hline \multirow[t]{2}{*}{ EQ-5D-3L } & \multicolumn{5}{|l|}{ EQ-5D-5L } \\
\hline & No problems & Slight problems & Moderate problems & Severe problems & Unable/extreme \\
\hline \multicolumn{6}{|l|}{ Mobility } \\
\hline No problems $(\mathrm{n}=363)$ & $321(88.4)$ & $37(10.2)$ & $5(1.4)$ & $\mathbf{0}(\mathbf{0 . 0})$ & $\mathbf{0}(\mathbf{0 . 0})$ \\
\hline Some problems $(n=137)$ & $15(10.9)$ & $72(52.6)$ & $39(28.5)$ & $10(7.3)$ & $1(0.7)$ \\
\hline Unable/extreme $(\mathrm{n}=1)$ & $\mathbf{0}(\mathbf{0 . 0})$ & $0(\mathbf{0 . 0})$ & $0(\mathbf{0 . 0})$ & $1(100.0)$ & $0(0.0)$ \\
\hline \multicolumn{6}{|l|}{ Self-care } \\
\hline No problems $(n=469)$ & $461(98.3)$ & $8(1.7)$ & $\mathbf{0}(\mathbf{0 . 0})$ & $\mathbf{0}(\mathbf{0 . 0})$ & $\mathbf{0}(\mathbf{0 . 0})$ \\
\hline Some problems $(\mathrm{n}=31)$ & $4(12.9)$ & $18(58.1)$ & $6(19.4)$ & $3(9.7)$ & $\mathbf{0}(\mathbf{0 . 0})$ \\
\hline Unable/extreme $(\mathrm{n}=1)$ & $\mathbf{0}(\mathbf{0 . 0})$ & $\mathbf{0}(\mathbf{0 . 0})$ & $\mathbf{0}(\mathbf{0 . 0})$ & $1(100.0)$ & $0(0.0)$ \\
\hline \multicolumn{6}{|l|}{ Usual activities } \\
\hline No problems $(\mathrm{n}=360)$ & $334(92.8)$ & $25(6.9)$ & $1(0.3)$ & $\mathbf{0}(\mathbf{0 . 0})$ & $\mathbf{0}(\mathbf{0 . 0})$ \\
\hline Some problems $(n=134)$ & $23(17.2)$ & $69(51.5)$ & $33(6.7)$ & $9(6.7)$ & $\mathbf{0}(\mathbf{0 . 0})$ \\
\hline Unable/extreme $(\mathrm{n}=7)$ & $\mathbf{0}(\mathbf{0 . 0})$ & $1(14.3)$ & $\mathbf{0}(\mathbf{0 . 0})$ & $4(57.1)$ & $2(28.6)$ \\
\hline \multicolumn{6}{|l|}{ Pain/discomfort } \\
\hline No problems $(\mathrm{n}=240)$ & $167(69.6)$ & $71(29.6)$ & $1(0.4)$ & $1(0.4)$ & $\mathbf{0}(\mathbf{0 . 0})$ \\
\hline Some problems $(n=242)$ & $18(7.4)$ & $158(65.3)$ & $56(23.1)$ & $10(4.1)$ & $\mathbf{0}(\mathbf{0 . 0})$ \\
\hline Unable/extreme $(\mathrm{n}=19)$ & $\mathbf{0}(\mathbf{0 . 0})$ & $1(5.3)$ & $5(26.3)$ & $9(47.4)$ & $4(21.1)$ \\
\hline \multicolumn{6}{|l|}{ Anxiety/depression } \\
\hline No problems $(\mathrm{n}=383)$ & $359(93.7)$ & $20(5.2)$ & $4(1.0)$ & $\mathbf{0}(\mathbf{0 . 0})$ & $\mathbf{0}(\mathbf{0 . 0})$ \\
\hline Some problems $(n=103)$ & $14(13.6)$ & $63(61.2)$ & $20(19.4)$ & $6(5.8)$ & $\mathbf{0}(\mathbf{0 . 0})$ \\
\hline Unable/extreme $(n=15)$ & $\mathbf{0}(\mathbf{0 . 0})$ & $\mathbf{0}(\mathbf{0 . 0})$ & $4(26.7)$ & $9(60.0)$ & $2(13.3)$ \\
\hline
\end{tabular}

Inconsistencies (marked in bold) are defined as differences of more than one between 3 and 5L response categories

Table 4 EQ-5D-5L and EQ VAS reliability, standard error of measurement and smallest detectable change $(n=164)$

\begin{tabular}{|c|c|c|c|c|c|c|c|c|c|}
\hline & \multicolumn{5}{|c|}{ Frequencies $\%$ test, retest } & \multirow[b]{2}{*}{$\begin{array}{l}\text { Correla- } \\
\text { tion/Kap- } \\
\mathrm{pa}^{\mathrm{c}}\end{array}$} & \multirow[b]{2}{*}{ SEM $^{\mathrm{d}}$} & \multirow[b]{2}{*}{$\begin{array}{l}\mathrm{SDC}^{\mathrm{e}} \text { indi- } \\
\text { vidual }\end{array}$} & \multirow[b]{2}{*}{$\mathrm{SDC}^{\mathrm{e}}$ group } \\
\hline & No problems & $\begin{array}{l}\text { Slight prob- } \\
\text { lems }\end{array}$ & $\begin{array}{l}\text { Moderate } \\
\text { problems }\end{array}$ & $\begin{array}{l}\text { Severe prob- } \\
\text { lems }\end{array}$ & $\begin{array}{l}\text { Unable/ } \\
\text { extreme }\end{array}$ & & & & \\
\hline Mobility & $72.6,78.0$ & $17.7,14.0$ & $7.9,5.5$ & $1.8,2,4$ & - & 0.83 & 0.29 & 0.80 & 0.06 \\
\hline Self-care & $94.5,90.9$ & $4.9,8.5$ & $0.6,0.6$ & - & - & 0.57 & 0.19 & 0.53 & 0.04 \\
\hline $\begin{array}{l}\text { Usual activi- } \\
\text { ties }\end{array}$ & $81.1,75.0$ & $11.0,17.7$ & $6.1,4.9$ & $1.8,2,4$ & - & 0.75 & 0.34 & 0.94 & 0.07 \\
\hline $\begin{array}{l}\text { Pain/discom- } \\
\text { fort }\end{array}$ & $39.0,47.0$ & $47.0,40.9$ & $11.0,10.4$ & $2.4,1.2$ & $0.6,0.6$ & 0.76 & 0.37 & 1.02 & 0.08 \\
\hline \multirow{2}{*}{$\begin{array}{l}\text { Anxiety/ } \\
\text { depression }\end{array}$} & $79.3,79.9$ & $14.0,15.2$ & $4.3,3.0$ & $1.8,1.2$ & $0.6,0.6$ & 0.86 & 0.25 & 0.70 & 0.05 \\
\hline & \multicolumn{2}{|l|}{ Mean (SD) test } & \multicolumn{3}{|c|}{ Mean (SD) retest } & & & & \\
\hline $\begin{array}{l}\text { EQ-5D } \\
\text { index }^{\text {a, b }}\end{array}$ & \multicolumn{2}{|l|}{$0.83(0.17)$} & \multicolumn{3}{|l|}{$0.85(0.18)$} & 0.82 & 0.07 & 0.20 & 0.02 \\
\hline EQ VAS ${ }^{b}$ & \multicolumn{2}{|l|}{$83.28(14.80)$} & \multicolumn{3}{|c|}{$80.62(16.19)$} & 0.76 & 7.37 & 20.44 & 1.88 \\
\hline
\end{tabular}

${ }^{\mathrm{a}} 164(90.1 \%)$ of the 182 respondents correctly completed the EQ-5D-5L at test and retest. 118 respondents correctly completed the EQ VAS at test and retest

${ }^{b}$ EQ-5D-5L index scores range from -0.57 to 1 where 1 is the best possible health state, EQ VAS scores range from $0-100$ where 100 is the best possible health state

${ }^{\mathrm{c}}$ Intraclass correlation (index and EQ VAS), kappa with quadratic weighting (dimensions)

${ }^{\mathrm{d}}$ Standard error of measurement

${ }^{\text {e }}$ Smallest detectable change 
EQ VAS had an SEM of 7.37, and SDCs of 20.44 and 1.88 for individuals and groups, respectively.

\section{Validity}

Table 5 shows the correlations between the $3 \mathrm{~L}$ and $5 \mathrm{~L}$ dimension, index, and EQ VAS scores. Correlations between EQ-5D index scores and contributing dimensions ranged from 0.40 to 0.87 , and from 0.42 to 0.88 , for the $3 \mathrm{~L}$ and $5 \mathrm{~L}$, respectively. Except for anxiety/depression, which had the same level for both versions, the 5L dimensions and index scores had slightly higher correlations with those for the EQ VAS. Correlations between corresponding $3 \mathrm{~L}$ and $5 \mathrm{~L}$ dimension scores ranged from 0.70 to 0.82 for pain/discomfort and self-care, respectively. 3L dimension scores generally had slightly higher correlations with those for the $5 \mathrm{~L}$ than with other $3 \mathrm{~L}$ dimension scores.

Table 6 shows that correlations of $\geq 0.6$ were found between $3 \mathrm{~L}, 5 \mathrm{~L}$ and SF-36 scores assessing very similar aspects of health. Correlations with the three ankle-specific scores were of a similar magnitude for those of the EQ-5D assessing overlapping aspects of health: mobility, usual activities, and pain/discomfort. Correlations of $\geq 0.6$ were also found for the two index scores and those for SF-36 general health, SF-36 domains mostly related to physical health and the ankle-specific scores. Two of the correlations for both index scores were slightly lower than expected (0.58-0.59). For the scores assessing related but dissimilar constructs, all but two correlations were in the range $<0.60$ and $\geq 0.30$. The exception was pain/discomfort at 0.61 for both EQ-5D versions. All but one of the remaining correlations (3L pain/discomfort and SF-36 mental health) were in the expected range of $<0.50$ and $\geq 0.20$ for scores assessing moderately related but dissimilar constructs. There were 11 correlations of the same size but the majority (44/66) were slightly higher for the $5 \mathrm{~L}$ compared to the $3 \mathrm{~L}$ scores. The differences in correlation were largest for the anklespecific instruments. Compared to both index scores, EQ VAS scores had lower correlations with those for the SF-36 and ankle-specific instruments. These were slightly lower than expected for the ankle-specific instruments and SF-36 role-physical and bodily pain domains.

\section{Discussion}

The study found that the two EQ-5D versions had satisfactory data quality, reliability, and validity. In general, the differences in performance of the two versions was not large, but the $5 \mathrm{~L}$ performed slightly better across several important measurement criteria. The concurrent nature of the evaluation reported here represents the strongest available evidence for choosing the $5 \mathrm{~L}$ version in long-term follow-up after ankle surgery.

Across 5L dimensions, respondents used four or five response categories and hence described a greater range of health states than for the $3 \mathrm{~L}$ (69 compared to 38). Very few respondents had dimension scores corresponding to the lowest possible health, but the $5 \mathrm{~L}$ had fewer such responses for pain/discomfort and anxiety/depression, the former being an important dimension for ankle fracture. One systematic review of studies comparing the two versions across diverse illness groups and the general population, reported similar

Table 5 Listwise Spearman correlations for EQ-5D-3L, 5L and EQ VAS scores $(n=501)$

\begin{tabular}{|c|c|c|c|c|c|c|c|c|}
\hline & & & EQ-5D-3L & & & & & \\
\hline & $\begin{array}{l}\text { EQ-5D-5L } \\
\text { index }\end{array}$ & EQ VAS & $\begin{array}{l}\text { EQ-5D-3L } \\
\text { Index }\end{array}$ & Mobility & Self-care & Usual activities & Pain/discomfort & $\begin{array}{l}\text { Anxiety/ } \\
\text { depression }\end{array}$ \\
\hline EQ-5D-3L index & 0.84 & 0.57 & & & & & & \\
\hline Mobility & 0.66 & 0.48 & 0.72 & & & & & \\
\hline Self-care & 0.40 & 0.32 & 0.40 & 0.37 & & & & \\
\hline Usual activities & 0.66 & 0.48 & 0.73 & 0.66 & 0.43 & & & \\
\hline Pain/discomfort & 0.68 & 0.43 & 0.87 & 0.54 & 0.20 & 0.53 & & \\
\hline Anxiety/depression & 0.50 & 0.39 & 0.55 & 0.28 & 0.29 & 0.31 & 0.23 & \\
\hline EQ-5D-5L index & & 0.58 & 0.82 & 0.66 & 0.38 & 0.63 & 0.71 & 0.51 \\
\hline Mobility & 0.79 & 0.50 & 0.72 & 0.75 & 0.40 & 0.70 & 0.59 & 0.31 \\
\hline Self-care & 0.42 & 0.35 & 0.40 & 0.39 & 0.82 & 0.43 & 0.22 & 0.31 \\
\hline Usual activities & 0.74 & 0.49 & 0.71 & 0.71 & 0.44 & 0.78 & 0.57 & 0.33 \\
\hline Pain/discomfort & 0.88 & 0.48 & 0.72 & 0.56 & 0.31 & 0.57 & 0.70 & 0.30 \\
\hline Anxiety/depression & 0.56 & 0.39 & 0.45 & 0.27 & 0.27 & 0.29 & 0.19 & 0.81 \\
\hline
\end{tabular}

Undertaken separately for the EQ-VAS, which had a lower number of respondents $(n=363)$

All correlations are significant $(\mathrm{p}<0.01)$ 


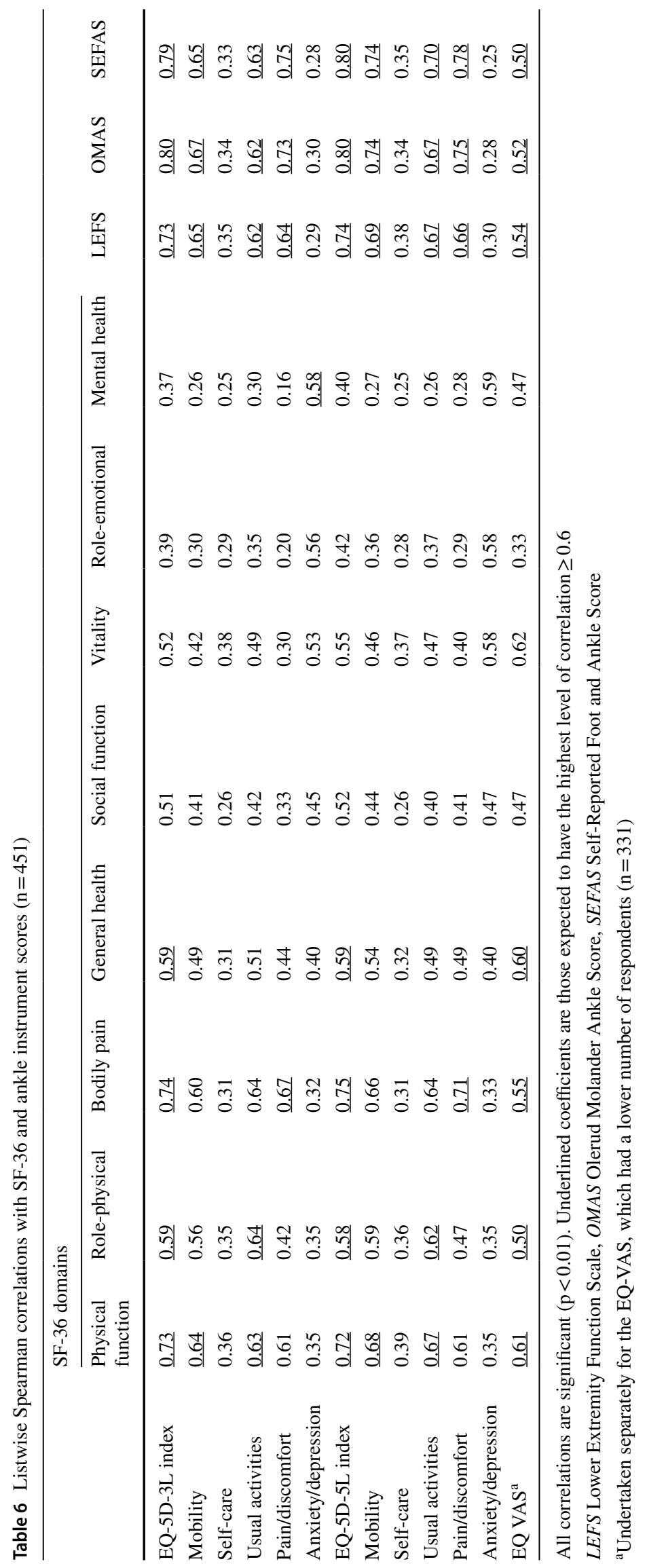


improvements for the $5 \mathrm{~L}$, the largest being for the pain/discomfort dimension [10].

Given the long-term follow-up nature of the survey, a high proportion of respondents scoring at the best possible levels of health, was expected. There was little difference between the two versions for three dimensions, but responses at the ceiling were up to $11 \%$ lower for the $5 \mathrm{~L}$ compared to the $3 \mathrm{~L}$ for the dimensions of mobility and pain/discomfort, and statistically significant. These are important aspects of health in this group of respondents, including long-term follow up. The systematic review of $3 \mathrm{~L}$ and $5 \mathrm{~L}$ comparisons did not include long-term follow-up populations, and larger differences in ceiling effects were found; up to $17 \%$ of rmobility and 30\% for self-care dimensions [10]. Statistically significant reductions in ceiling effects for the $5 \mathrm{~L}$ compared to the $3 \mathrm{~L}$ have been reported by more recent studies, with pain/discomfort often being the largest [19, 35-38].

Shannon's indices showed that the $5 \mathrm{~L}$ outperformed the $3 \mathrm{~L}$ in tests of classification efficiency. These results follow the findings of a systematic review based on 14 studies [10] and more recent studies reporting tests of classification efficiency $[14,15,19,20,35-37,39,40]$.

The very few responses to the lowest levels of health limited the assessment of response consistency across the $3 \mathrm{~L}$ and 5L. The greatest proportion of inconsistencies related to pain/discomfort and anxiety/depression where up to 5 respondents reported extreme problems on the $3 \mathrm{~L}$ and moderate problems on the $5 \mathrm{~L}$. This was followed by the most obvious pattern of inconsistencies across all five dimensions for respondents reporting some problems on the $3 \mathrm{~L}$ and no problems on the $5 \mathrm{~L}$. There was no evidence that the ordering of the $3 \mathrm{~L}$ and $5 \mathrm{~L}$ within the questionnaire affected the level of response inconsistencies.

The test-retest design was limited to the $5 \mathrm{~L}$, which was considered appropriate given that evidence from a range of general and patient populations supports its application in preference to the $3 \mathrm{~L}[10,14-20]$. There was no evidence for systematic differences between test and retest scores. The levels of kappa for dimension scores, and correlation for index and EQ VAS scores, largely met the 0.7 criterion [32] and were higher than most estimates reported by a systematic review of EQ-5D measurement properties [10]. The dimension of self-care was below the criterion, but it had the lowest SEM across dimensions. Reliability levels often limit the interpretation of single items, here in the form of EQ-5D dimension scores, at the group and particularly the individual level. These results were no exception but are satisfactory.

Along with the EQ-5D, the SF-36 is the most widely tested and used PROM [13, 27]. Being a health profile measure, which assesses several important aspects of health, further enhances its use in tests of validity that included EQ-5D dimension as well as in index scores. The inclusion of three widely used ankle-specific instruments [7] further contributed to validity testing. With very few exceptions, the expected correlations were found. Overall, the statistically significant correlations show that the EQ-5D is picking up adverse and other aspects of health across instruments that are widely used in ankle research and that the $5 \mathrm{~L}$ improves upon the $3 \mathrm{~L}$ in this respect.

\section{Study strengths and limitations}

The concurrent nature of the $3 \mathrm{~L}$ and $5 \mathrm{~L}$ comparison is an important study strength, which gives the best available evidence for comparative measurement performance [13]. Moreover, the ordering of the questionnaires was randomized so that half the respondents completed the $3 \mathrm{~L}$ first, and half, the $5 \mathrm{~L}$ first. The inclusion of widely used generic and ankle-specific PROMs was a further strength, which allowed extensive testing for validity. The study followed widely recognized recommendations for assessing the measurement properties of PROMs in general [21, 32] and the EQ-5D [10].

The main study limitation stems from it being a longterm follow-up. It is important that the EQ-5D is assessed for measurement properties at other clinically important follow-up periods. Given the results of this and other studies [10, 14-20, 35-40], further testing should focus on the 5L. This limitation also meant that it was not possible to assess the EQ-5D along with the other instruments, for responsiveness to change. This is an important measurement property that further informs the selection of instruments for evaluative studies including clinical trials [7, 21]. The $59 \%$ response rate to the survey questionnaire is acceptable, but some statistically significant differences between respondents and non-respondents were found [22].

Limitations of the test-retest design include the six-week interval between test and retest necessitated by practical considerations, and absence of health transition questions. The EQ-5D asks about health today, and hence, the reliability estimates produced by this study might well be biased due the study design. Intervals of between one and three weeks were found across previous studies assessing the reliability of the EQ-5D [10]. Transition questions, which focus on relevant aspects of health, are widely used in test-retest studies as a means of identifying respondents whose health has changed between test and retest [41]. The absence of such a question is of particular importance given the six-week interval and changes in health that may have taken place for some respondents. Given that the EQ-5D focuses on health today, the removal of such respondents from the analysis may have contributed to improved test-retest estimates. 


\section{Conclusions}

The EQ-5D is the most widely used short generic instrument suitable for use in economic evaluation including cost per QALY calculations. It is widely used in patients with ankle fractures including clinical trials of surgery, but there is limited evidence supporting its application. This is the first study to test the measurement properties of either the $3 \mathrm{~L}$ or $5 \mathrm{~L}$ version of the instrument, following surgery for ankle fracture and in ankle problems more generally. The $5 \mathrm{~L}$ version is increasingly used and hence, this concurrent evaluation of both versions is timely. Findings following testing for data quality, reliability and validity support the use of the $5 \mathrm{~L}$ in preference to the $3 \mathrm{~L}$ version but further testing, including responsiveness to change, is recommended at clinically relevant follow-up periods.

Acknowledgements Thanks to Markus G. Naumann, Ulf Sigurdsen and Stein Erik Utvåg for their contributions to planning and data collection in the study, and for making the data set available to the authors.

Author contributions KS participated in designing the cross-sectional postal survey and was responsible for data collection. AMG performed the statistical analysis and drafted the manuscript. The co-author commented on this and subsequent versions of the manuscript. Both authors read and approved the final manuscript.

Funding Open access funding provided by Norwegian Institute of Public Health (FHI). AMG is funded by The Research Council of Norway (Project Number 262673). The project was partially funded by The Sophies Minde Foundation and Østfold Hospital. The sponsors had no involvement in study planning, collection, analysis, or interpretation of the data, or in the preparation, or approval of the manuscript.

Data availability The datasets used and/or analyzed during the current study are available from the corresponding author on reasonable request.

\section{Declarations}

Conflict of interest The authors declare that they have no conflict of interest.

Open Access This article is licensed under a Creative Commons Attribution 4.0 International License, which permits use, sharing, adaptation, distribution and reproduction in any medium or format, as long as you give appropriate credit to the original author(s) and the source, provide a link to the Creative Commons licence, and indicate if changes were made. The images or other third party material in this article are included in the article's Creative Commons licence, unless indicated otherwise in a credit line to the material. If material is not included in the article's Creative Commons licence and your intended use is not permitted by statutory regulation or exceeds the permitted use, you will need to obtain permission directly from the copyright holder. To view a copy of this licence, visit http://creativecommons.org/licenses/by/4.0/.

\section{References}

1. Szende, A., Janssen, B., \& Cabases, J. (2014). Self-Reported Population Health: An International Perspective based on EQ-5D. Springer.

2. Garratt, A. M., Hansen, T. M., Augestad, L. A., Rand, K., \& Stavem, K. (2021). Norwegian population norms for the EQ5D-5L: results from a general population survey. Quality of Life Research, 16, 1-10. https://doi.org/10.1007/s11136-021-02938-7

3. Devlin, N. J., \& Brooks, R. (2017). EQ-5D and the EuroQol group: past, present and future. Applied Health Economics and Health Policy, 15(2), 127-137. https://doi.org/10.1007/ s40258-017-0310-5

4. Solberg, T. K., Olsen, J. A., Ingebrigtsen, T., Hofoss, D., \& Nygaard, O. P. (2005). Health-related quality of life assessment by the EuroQol-5D can provide cost-utility data in the field of low-back surgery. European Spine Journal, 14(10), 1000-1007. https://doi.org/10.1007/s00586-005-0898-2

5. Henricson, A., Kamrad, I., Rosengren, B., \& Carlsson, Å. (2016). Bilateral Arthrodesis of the Ankle Joint: Self-Reported Outcomes in 35 Patients From the Swedish Ankle Registry. The Journal of Foot and Ankle Surgery, 55(6), 1195-1198. https://doi.org/10. 1053/j.jfas.2016.07.014

6. Nilsson, E., Orwelius, L., \& Kristenson, M. (2016). Patientreported outcomes in the Swedish National quality registers. Journal of Internal Medicine, 279(2), 141-153. https://doi.org/ 10.1111/joim.12409

7. Garratt, A. M., Naumann, M. G., Sigurdsen, U., Utvåg, S. E., \& Stavem, K. (2018). Evaluation of three patient reported outcome measures following operative fixation of closed ankle fractures. BMC Musculoskeletal Disorders, 19(1), 134. https://doi.org/10. 1186/s12891-018-2051-5

8. Cöster, M. C., Bremander, A., Rosengren, B. E., Magnusson, H., Carlsson, A., \& Karlsson, M. K. (2014). Validity, reliability, and responsiveness of the Self-reported Foot and Ankle Score (SEFAS) in forefoot, hindfoot, and ankle disorders. Acta Othopaedica, 85(2), 187-194. https://doi.org/10.3109/17453674.2014. 889979

9. Dawson, J., Boller, I., Doll, H., Lavis, G., Sharp, R., Cooke, P., \& Jenkinson, C. (2012). Responsiveness of the Manchester-Oxford Foot Questionnaire (MOXFQ) compared with AOFAS, SF-36 and EQ-5D assessments following foot or ankle surgery. The Journal of Bone and Joint Surgery British, 94(2), 215-221. https://doi.org/ 10.1302/0301-620X.94B2.27634

10. Buchholz, I., Janssen, M. F., Kohlmann, T., \& Feng, Y. S. (2018). A Systematic Review of studies comparing the measurement properties of the three-level and five-level versions of the EQ-5D. Pharmaco Economics, 36(6), 645-661. https://doi.org/10.1007/ s40273-018-0642-5

11. Viberg, B., Kleven, S., Hamborg-Petersen, E., \& Skov, O. (2016). Complications and functional outcome after fixation of distal tibia fractures with locking plate - A multicentre study. Injury, 47(7), 1514-1518. https://doi.org/10.1016/j.injury.2016.04.025

12. Matthews, P. A., Scammell, B. E., Ali, A., Coughlin, T., Nightingale, J., Khan, T., \& Ollivere, B. J. (2018). Early motion and directed exercise (EMADE) versus usual care post ankle fracture fixation: Study protocol for a pragmatic randomised controlled trial. Trials, 19(1), 304. https://doi.org/10.1186/ s13063-018-2691-7

13. Garratt, A., Schmidt, L., Mackintosh, A., \& Fitzpatrick, R. (2002). Quality of life measurement: Bibliographic study of patient assessed health outcome measures. British Medical Journal, 324(7351), 1417. https://doi.org/10.1136/bmj.324.7351.1417

14. Janssen, M. F., Bonsel, G. J., \& Luo, N. (2018). Is EQ-5D-5L Better Than EQ-5D-3L? A head-to-head comparison of descriptive 
systems and value sets from seven countries. PharmacoEconomics, 36(6), 675-697. https://doi.org/10.1007/s40273-018-0623-8

15. Martí-Pastor, M., Pont, A., Ávila, M., Garin, O., Vilagut, G., Forero, C. G., Pardo, Y., Tresserras, R., Medina-Bustos, A., Garcia-Codina, O., Cabasés, J., Rajmil, L., Alonso, J., \& Ferrer, M. (2018). Head-to-head comparison between the EQ5D-5L and the EQ-5D-3L in general population health surveys. Population Health Metrics, 16(1), 14. https://doi.org/10.1186/ s12963-018-0170-8

16. Gandhi, M., Ang, M., Teo, K., Wong, C. W., Wei, Y. C., Tan, R. L., Janssen, M. F., \& Luo, N. (2019). EQ-5D-5L is more responsive than EQ-5D-3L to treatment benefit of cataract surgery. The Patient, 12(4), 383-392. https://doi.org/10.1007/ s40271-018-00354-7

17. Gray, C. F. (2019). CORR Insights ${ }^{\circledR}:$ The EQ-5D-5L is Superior to the $-3 \mathrm{~L}$ version in measuring health-related quality of life in patients awaiting THA or TKA. Clinical Orthopaedics and Related Research, 477(7), 1645-1647. https://doi.org/10.1097/ CORR.0000000000000753

18. Jin, X., Al Sayah, F., Ohinmaa, A., Marshall, D. A., \& Johnson, J. A. (2019). Responsiveness of the EQ-5D-3L and EQ-5D-5L in patients following total hip or knee replacement. Quality of Life Research, 28(9), 2409-2417. https://doi.org/10.1007/ s11136-019-02200-1

19. Rencz, F., Lakatos, P. L., Gulácsi, L., Brodszky, V., Kürti, Z., Lovas, S., Banai, J., Herszényi, L., Cserni, T., Molnár, T., Péntek, M., \& Palatka, K. (2019). Validity of the EQ-5D-5L and EQ5D-3L in patients with Crohn's disease. Quality of Life Research, 28(1), 141-152. https://doi.org/10.1007/s11136-018-2003-4

20. Shafie, A. A., Vasan Thakumar, A., Lim, C. J., \& Luo, N. (2019). Psychometric performance assessment of Malay and Malaysian English version of EQ-5D-5L in the Malaysian population. Quality of Life Research, 28(1), 153-162. https://doi.org/10.1007/ s11136-018-2027-9

21. Mokkink, L. B., Terwee, C. B., Patrick, D. L., Alonso, J., Stratford, P. W., Knol, D. L., Bouter, L. M., \& de Vet, H. C. (2010). The COSMIN checklist for assessing the methodological quality of studies on measurement properties of health status measurement instruments: An international Delphi study. Quality of Life Research, 19(4), 539-549. https://doi.org/10.1007/ s11136-010-9606-8

22. Naumann, M. G., Sigurdsen, U., Utvåg, S. E., \& Stavem, K. (2017). Associations of timing of surgery with postoperative length of stay, complications, and functional outcomes 3-6 years after operative fixation of closed ankle fractures. Injury, 48(7), 1662-1669. https://doi.org/10.1016/j.injury.2017.03.039

23. Statens Legemiddelverk. (2018). Guidelines for the submission of documentation for single technology assessment (STA) of pharmaceuticals. Retrieved November 20, 2020, from https://legem iddelverket.no/english/public-funding-and-pricing/documentat ion-for-sta/guidelines-for-the-submission-of-documentation-forsingle-technology-assessment-sta-of-pharmaceuticals.

24. Dolan, P. (1997). Modeling valuations for EuroQol health states. Medical Care, 35(11), 1095-1108. https://doi.org/10.1097/00005 650-199711000-00002

25. van Hout, B., Janssen, M. F., Feng, Y. S., Kohlmann, T., Busschbach, J., Golicki, D., et al. (2012). Interim scoring for the EQ5D-5L: Mapping the EQ-5D-5L to EQ-5D-3L value sets. Value Health, 15(5), 708-715. https://doi.org/10.1016/j.jval.2012.02. 008

26. Ware, J. E., \& Sherbourne, C. D. (1992). The MOS 36-item ShortForm Health Survey (SF-36) I: Conceptual framework and item selection. Medical Care, 30(6), 473-483.

27. Garratt, A. M., \& Stavem, K. (2017). Measurement properties and normative data for the Norwegian SF-36: Results from a general population survey. Health and Quality of Life Outcomes, 15(1), 51. https://doi.org/10.1186/s12955-017-0625-9

28. Binkley, J. M., Stratford, P. W., Lott, S. A., \& Riddle, D. L. (1999). The Lower Extremity Functional Scale (LEFS): scale development, measurement properties, and clinical application. North American Orthopaedic Rehabilitation Research Network. Physical Therapy, 79(4), 371-383.

29. Olerud, C., \& Molander, H. (1984). A scoring scale for symptom evaluation after ankle fracture. Archives of Orthopaedic and Traumatic Surgery, 103(3), 190-194. https://doi.org/10.1007/BF004 35553

30. Hosman, A. H., Mason, R. B., Hobbs, T., \& Rothwell, A. G. (2007). A New Zealand national joint registry review of 202 total ankle replacements followed for up to 6 years. Acta Orthopaedica, 78(5), 584-591. https://doi.org/10.1080/17453670710014266

31. Terwee, C. B., Bot, S. D., de Boer, M. R., van der Windt, D. A., Knol, D. L., Dekker, J., et al. (2007). Quality criteria were proposed for measurement properties of health status questionnaires. Journal of Clinical Epidemiology, 60(1), 34-42.

32. Prinsen, C., Mokkink, L. B., Bouter, L. M., Alonso, J., Patrick, D. L., de Vet, H., \& Terwee, C. B. (2018). COSMIN guideline for systematic reviews of patient-reported outcome measures. Quality of Life Research, 27(5), 1147-1157. https://doi.org/10.1007/ s11136-018-1798-3

33. Fleiss, J. L., \& Cohen, J. (1973). The equivalence of weighted kappa and the intraclass correlation coefficient as measures of reliability. Educational and Psychological Measurement., 33, 613-619.

34. Chiarotto, A., Terwee, C. B., Kamper, S. J., Boers, M., \& Ostelo, R. W. (2018). Evidence on the measurement properties of healthrelated quality of life instruments is largely missing in patients with low back pain: A systematic review. Journal of Clinical Epidemiology, 102, 23-37. https://doi.org/10.1016/j.jclinepi.2018.05. 006

35. Bhadhuri, A., Kind, P., Salari, P., Jungo, K. T., Boland, B., Byrne, S., et al. (2020). Measurement properties of EQ-5D-3L and EQ$5 \mathrm{D}-5 \mathrm{~L}$ in recording self-reported health status in older patients with substantial multimorbidity and polypharmacy. Health and Quality of Life Outcomes, 8, 317.

36. Christiansen, A. S. J., Møller, M. L. S., Kronborg, C., Haugan, K. J., Køber, L., Højberg, S., et al. (2021). Comparison of the three-level and the five-level versions of the EQ-5D. European Journal of Health Economics, 22(4), 621-628. https://doi.org/10. 1007/s10198-021-01279-z

37. Bató, A., Brodszky, V., Gergely, L. H., Gáspár, K., Wikonkál, N., Kinyó, Á., et al. (2021). The measurement performance of the EQ-5D-5L versus EQ-5D-3L in patients with hidradenitis suppurativa. Quality of Life Research, 30(5), 1477-1490. https://doi. org/10.1007/s11136-020-02732-x

38. Yu, H., Zeng, X., Sui, M., Liu, R., Tan, R. L., Yang, J., Huang, W., \& Luo, N. (2021). A head-to-head comparison of measurement properties of the EQ-5D-3L and EQ-5D-5L in acute myeloid leukemia patients. Quality of Life Research, 30(3), 855-866. https:// doi.org/10.1007/s11136-020-02644-w

39. Jin, X., Al Sayah, F., Ohinmaa, A., Marshall, D. A., Smith, C., \& Johnson, J. A. (2019). The EQ-5D-5L Is Superior to the -3L version in measuring health-related quality of life in patients awaiting THA or TKA. Clinical Orthopaedics and Related Research, 477(7), 1632-1644. https://doi.org/10.1097/CORR.0000000000 000662

40. Zhu, J., Yan, X. X., Liu, C. C., Wang, H., Wang, L., Cao, S. M., et al. (2021). Comparing EQ-5D-3L and EQ-5D-5L performance in common cancers: Suggestions for instrument choosing. Quality of Life Research, 30(3), 841-854. https://doi.org/10.1007/ s11136-020-02636-w 
41. Terwee, C. B., Peipert, J. D., Chapman, R., Lai, J. S., Terluin, B., Cella, D., et al. (2021). Minimal important change (MIC): A conceptual clarification and systematic review of MIC estimates of PROMIS measures. Quality of life Research, 30(10), 2729-2754. https://doi.org/10.1007/s11136-021-02925-y
Publisher's Note Springer Nature remains neutral with regard to jurisdictional claims in published maps and institutional affiliations. 